\title{
Perception and Belief on Cannabinoids: A Comparative Study of Rheumatology Patients and Primary Care Physicians on the Use of Cannabinoids for Pain Management
}

\author{
Nibha Jain ${ }^{1}$, Neelima Reddy Kunam ${ }^{2}$, Arumugam Moorthy ${ }^{3,1}$ \\ 1. Rheumatology, University Hospitals of Leicester NHS Trust, Leicester, GBR 2. Medicine, University Hospitals of \\ Leicester NHS Trust, Leicester, GBR 3. Medicine, College of Life Sciences, Leicester Medical School, University of \\ Leicester, Leicester, GBR
}

Corresponding author: Arumugam Moorthy, moorthyarumugam@hotmail.com

\section{Abstract \\ Introduction}

With the recent increase in popularity of cannabinoids in the management of chronic pain, the inquisitiveness among our patients and health care professionals are probably now at its peak. Many treating health care professionals in their clinical practice come across patients who either use cannabinoids or are interested in their efficacy and side effects. As there is paucity of data and research about their use in rheumatology, patient's self-reported responses and experience of primary care physicians (General Practitioners [GPs]) can guide in expanding our knowledge.

\section{Methods}

Ours was an observational, cross-sectional study among rheumatology patients and GPs in the Leicestershire area. Initial questionnaire was designed by authors addressing demographics, knowledge, experience and perception. This was piloted among patients and GPs and improvised, redesigned and used for the study. The study design consisted of two arms: first arm including GPs and second arm rheumatology patients.

\section{Results}

Arm 1 consisted of 100 GPs with median age group of 30-40 years. 34\% GPs experienced their patients inquiring about cannabinoids. $78 \%$ did not believe cannabinoids benefited the patients. On a scale of 0-10, the mean benefit in managing pain $3.2+2.5$. Arm 2 consisted of 102 patients. $16 \%$ reported using cannabinoids for managing their chronic pain. The users reported significant improvement in pain compared to non-users ( $\mathrm{p}=0.002$ ). On comparing the perception of cannabinoids between GPs and patients, there was a statistically significant difference regarding awareness and effectiveness $(\mathrm{p}<0.001)$.

Review began 02/16/2021 Review ended 03/07/2021 Published 03/07/2021

\section{๑) Copyright 2021}

Jain et al. This is an open access article distributed under the terms of the Creative Commons Attribution License CC-BY 4.0., which permits unrestricted use, distribution, and reproduction in any medium, provided the original author and source are credited.

\section{Conclusion}

With the paucity of data and research about the use of cannabinoids in rheumatology, the patient selfreported responses provided an estimate as to their efficacy. This was significantly different from the GP perception. Disease and drug-focused research is need of the hour. To our knowledge, this is the First Single Centre study in the UK evaluating GP and rheumatology patient perception on cannabinoids.

Categories: Family/General Practice, Pain Management, Rheumatology

Keywords: synthetic cannabinoids, complementary alternative medicine, chronic pain management, arthritis and orthopaedic rheumatology

\section{Introduction}

Recently, there has been a lot of interest among patients, general public and clinicians regarding the use of cannabinoids for the management of chronic pain. Certain forms like cannabidiol (CBD) oils are being legitimately sold in high street. Cannabinoids have gained popularity among rheumatology patients and many treating clinicians frequently come across patients who are curious about it, are using it or even asking for a prescription. They are available both legally and through alternative sources in several forms such as oil, tablets, cake and coffee among others. While research on their therapeutic indications particularly in rheumatological conditions are limited, their popularity cannot be ignored.

Cannabis plants (C. sativa) are made up of more than 100 different cannabinoids, having different effects on the body. The most common forms known are CBD and tetrahydrocannabinol (THC). THC is the component responsible for psychoactive effects while CBD is devoid of this effect [1]. 
The endocannabinoid signalling system encompasses cannabinoid receptors, endocannabinoids and enzymes regulating the biosynthesis and inactivation of endocannabinoids. Cannabinoids are found in three settings: endogenous ligands or endocannabinoids (arachidonic acid derivatives); exogenous plant-derived phyto-cannabinoids and synthetic tricyclic terpenes [1].

There are two primary receptors CB1 and CB2 having very different and sometimes opposite actions. CB1 is primarily expressed in frontal cortex, basal ganglia and cerebellum and is responsible for the psychotropic effects of cannabis. Overall, CB1 activation exerts an inhibitory effect on the presynaptic cell. CB2 receptors are located peripherally on immunologic and musculoskeletal cells. it's the fine balance of effect of cannabis substance on these CB1 and CB2 receptors, that ultimately result in psychoactive or immunomodulatory effects [1]. THC is known to act more on CB1 while CBDs act on CB2 receptors.

There are several studies on the use of cannabinoids in rheumatic diseases. JWH133, a selective CB2 agonist, inhibited in-vitro production of cytokines in synoviocytes and reduced in-vivo arthritis score and bone destruction in collagen-induced arthritis (CIA) rat model [2]. Another CB2-selective agonist, HU-308, reduced synovial inflammation and joint destruction in CIA mice model [3].

Cannabis is currently a controlled drug as classified by the Misuse of Drugs Act 1971. Specific forms of cannabis are licensed for use in spasticity in adults with multiple sclerosis (MS), treatment-resistant epilepsy (Dravet and Lennox-Gastaut syndromes) and refractory vomiting secondary to chemotherapy. They require an initial prescription by a specialist medical practitioner and subsequent prescriptions may be issued by another prescriber (including General Practitioners [GPs]) as part of a shared care agreement [4]. On the other hand, use and sale of CBD products with $<1 \mathrm{mg}$ THC is legal in the UK [5].

Management of pain is an integral part of rheumatic diseases. Research on alternative therapies that can modulate pain and improve quality of life is essential. Paucity of data and RCT led to rejection of cannabinoids for management of chronic pain by NICE (NG144) guidelines [4].

Self-reported patient responses can assist healthcare providers and regulatory authorities in decisionmaking. These self-reported responses are unique indicators of impact of disease on the patient, helping in patient empowerment and necessary for determination of efficacy of the treatment. They can also be useful in the interpretation of clinical outcomes and treatment decision-making [6]. The NICE committee (2019) included the patient-reported improvement of spasticity in MS patients with the use of THC: CBD spray while licensing their use for the same indication [4].

In a self-administered questionnaire study conducted in the UK between 1998 and 2002, medicinal cannabis use was reported by patients with chronic pain (25\%), multiple sclerosis and depression (22\% each), arthritis (21\%) and neuropathy (19\%) [7]. In another self-reported prevalence of cannabinoid usage in 457 fibromyalgia patients, it was reported that $13 \%$ of fibromyalgia patients use cannabinoids, of whom $80 \%$ used herbal cannabis (marijuana), 24\% used prescription cannabinoids, and $3 \%$ used both herbal cannabis and prescription cannabinoids [8].

Despite frequent discussions in the media on the use of cannabinoids as an alternative therapeutic for chronic pain, physician's perspective and knowledge on using such therapies is still lacking in the UK. A Colorado-based survey of 114 healthcare providers concluded that though the providers frequently assess patients' marijuana use, they are uncomfortable and inconsistent in talking to patients about specific health effects [9].

In the absence of any consistent evidence-based guidelines and recommendations for cannabinoid use in rheumatology patients, we conducted a cross-sectional study comparing self-reported responses of rheumatology patients and GPs exploring their knowledge, experience and awareness of cannabinoids use in rheumatology.

While rheumatology patients are under specialist care for their specific illness, they are ultimately under the care of their GPs who were the initial port of call by the rheumatology patients for holistic health care requirements. Therefore in our study, we chose GPs as comparative arm for more comprehensive evaluation.

\section{Materials And Methods}

This was an observational, cross-sectional study among rheumatology patients and GPs in the Leicestershire area. Initial questionnaire was designed by authors addressing demographics, knowledge, experience and perception. This was piloted among rheumatology patients and GPs which was followed by improvisation and redesigned for the use in the study.

Our study design consisted of two arms with first arm including GPs and GP trainees while second arm had rheumatology patients attending general rheumatology clinics in Leicester Royal Infirmary (Figure 1). 


\section{Cureus}

\section{Study Design}

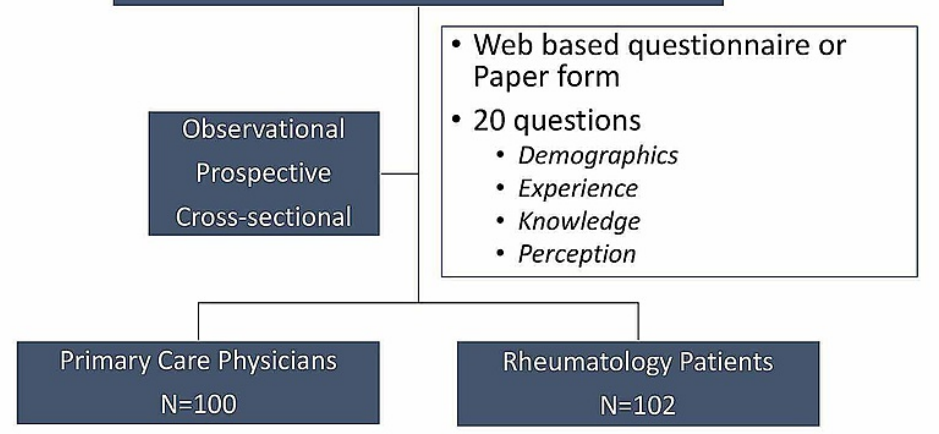

FIGURE 1: Study design.

Questionnaires were distributed from August 2019 to February 2020.

Arm 1: The form with 20 questions was divided into four sections covering demography, knowledge, experience and perception of cannabinoid usage for rheumatological conditions. The response was collected through web-based portal (Monkey Survey) which was sent through email. A reminder email was sent after one week. Paper-based forms were collected from GP trainees.

Arm 2: Patients were given a written participant information statement about the study and after taking informed consent and were invited to complete the anonymised questionnaire consisting of 20 questions with four sections on demography, knowledge, experience and perception of cannabinoids in managing their pain.

For grading answers, a 10-point Likert scale was used and for qualitative answers, participants were asked to rate in terms of "no help at all”, "somewhat helpful” and "extremely helpful”.

All collected information were compiled in the Microsoft excel sheet and then analysed using SPSS Software v23.0 version (IBM Corp., Armonk, NY). Demographic data were analyzed using descriptive statistics including Chi-square test for comparing the percentage. Numerical responses were tabulated and summarized using counts and percentages. To facilitate bivariate comparisons, we collapsed qualitative and Likert scale responses to helpful and not helpful (agree or disagree) and excluded the equivocal ("somewhat") responses.

A comparison between perception of GPs and patients regarding the efficacy of cannabinoids in managing rheumatological pain along with the opinion on availability of CBD via prescription was done.

We also compared the experiences of cannabinoid users and non-users to shine more light in to the subject.

\section{Results}

\section{Arm 1: GP response}

The response rate was $70 \%$. Total of 100 complete responses were analysed.

Section 1: Demographics

54\% were male with $47 \%$ GP trainees ( $51 \%$ GP) and two nurses. Most of the responders (51\%) had a clinical experience of up to 5 to 10 years while $21 \%$ had been practising for $>15$ years. Median age group was 30-40 years (Table 1). 


\section{Cureus}

n

Age group

25-30

$30-40$

40

$40-50$

27

$>50$

Male:female

Current position

GP trainees

47

GP

Nurses

Clinical experience

0-5 years

5 to 10 years

10 to 15 years

$>15$ years

Number of musculoskeletal patients seen per week

Up to 5 patients/week

Up to 10 patients/week

Up to 15 patients/week

Up to 20 patients/week

TABLE 1: Demographic profile of participant GPs.

GPs: General Practitioners.

Section 2: Experience

While $42 \%$ of GPs were aware of complementary medicine being used by rheumatology patients, only $11 \%$ prescribed cannabinoids in their practice indicating the majority usage as off-label.

Most (58\%) of the GPs replied that only $10 \%$ of their patients use any form of cannabinoids for their pain management while only $11 \%$ believed that $20 \%$ of their patients use complementary medicine for the management of chronic rheumatic pain. Only one replied $30 \%-50 \%$ of their patients use cannabinoids.

Fibromyalgia (FMS) was the most common (41\%) reported indication for their patients using cannabinoids, followed by rheumatoid arthritis (RA) (29\%) and osteoarthritis (OA) (20\%) (Table 3).

During routine clinics, 34\% GPs experienced their patients inquiring about cannabinoids. When asked about the frequency of these inquiries, 4\% GPs reported always, 22\% reported sometimes and $8 \%$ GPs reported rarely. 15\% GPs reported that patients have asked them to prescribe cannabinoids for their pain. Some of the other indications for which they have been asked to prescribe included insomnia and mood disorders.

On asking about self-reported side effects by the patients to their GPs, 8\% GPs reported adverse events which included constipation and anxiety.

Section 3: Knowledge 
Most of the GP trainees (85\%) accepted that they were unaware of the indications where cannabinoids can be recommended while $57 \%$ of experienced GPs (5-10 years' experience) were aware of the indications where cannabinoids are currently prescribed in NHS practice.

Only $21 \%$ reported cannabinoids being used for other medical conditions which included MS, epilepsy and malignancy-related pain. Interestingly few also reported chronic pain and depression as being reasons for cannabinoid usage among their patient group.

Section 4: Perception

Most GPs (78\%) did not believe that the use of cannabinoids benefited their patients much. 20\% believed it did not help at all. On a scale of $0-10$, the mean overall benefit they believed was $3.5+3.1$ (median 2.5 ). In terms of managing rheumatological pain their response was similar with mean benefit on a scale of $0-10$ being $3.2+2.5$ (median 4.5 ).

Only $14 \%$ would willingly recommend CBD usage in their practise; however, $27 \%$ agree it should be available as prescription in NHS.

\section{Arm 2: Rheumatology patient response}

Section 1: Demographics

Total of 102 responses were analyzed where $60 \%$ were females and the majority (45\%) had secondary school level education. Median age of patients using cannabinoids was 55 years. Almost half of the users were unemployed and only $33 \%$ were in full-time employment. $75 \%$ were Caucasians and $18 \%$ Asians. Very few Asian patients participated in the study and any stigma or cultural belief need to be explored in a diverse population of Leicestershire. RA (54\%) was the most common diagnosis followed by OA (23\%) and FMS (19\%). In terms of non-rheumatological co-existent mental health diagnosis, $42 \%$ reported suffering from depression and anxiety.

Most of the respondents (94\%) complained about having ongoing pain with the majority rating pain score between 6 and 8 on a Likert scale. While $42 \%$ were satisfied with their current therapy, 18\% of patients believed it was inadequate.

Of those that admitted to using cannabinoids for managing their pain (users), $88 \%$ were Caucasians and $38 \%$ reported alcohol consumption along with it. They were suffering from chronic illness with a mean duration of 6.25 years. There was no ethnicity difference noted in the use of CBD.

Section 2: Knowledge

$65 \%$ of responders are aware of complementary medicine and $16 \%$ accepted using cannabinoids for their pain. $60 \%$ of the patients who did not report using CBDs were interested to know more about them. None of the responders were aware of any drug interactions or adverse effects of cannabinoids.

Section 3: Experience

Most common form of cannabinoid used was oral preparation (70\%) followed by smoking or vaping (25\%) with only $5 \%$ using topically. $56 \%$ reported using them for more than three months and majority used daily. RA was the most common cause of chronic pain (68\%) followed by OA and FMS (25\% and 24\%, respectively) among users $(\mathrm{n}=16)$.

All of the users had ongoing pain with a mean intensity of 7 on 0-10 scale compelling cannabinoid usage. Only one reported having experienced any side effects.

It was noted that while the conventional therapy was somewhat helpful in managing their pain, cannabinoids were extremely helpful with all users strongly believing that they help in managing their pain almost completely (Figure 2). 


\section{Cureus}

\section{How much is current therapy helpful in managing your pain?}

\section{Some what Helpfu}

Extremely Helpful

Not helpful at all

$6 \%$

ow much is Cannabinoid therapy helpful in managing your pain?

Some what Helpful
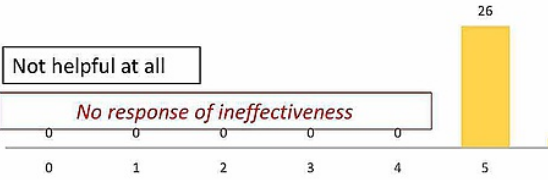

Extremely Helpful

FIGURE 2: Comparison of conventional and cannabinoid use in pain management.

On comparing self-reported responses of cannabinoid users vs non-users there were no significant differences in terms of demography, duration of illness or nature of disease. There was a significant difference $(\mathrm{p}=0.002)$ in improvement in pain among those who used cannabinoids along with conventional therapy compared to those on just conventional therapy (Table 2).

Comparison of patient-reported outcomes (PROM) among cannabinoid non-users and users in a rheumatology clinic

Age: median (average+ SD)

Male:female ratio

Caucasians

Asians

Alcohol

Smoking

Duration of illness

Diagnosis

Rheumatoid arthritis

Osteoarthritis

Fibromyalgia

Depression

Anxiety

Baseline pain VAS

Compiled improvement from therapy (conventional vs conventional + cannabinoids)

$$
\text { Non-users }(n=86) \quad \text { Users }(n=16)
$$

p-value

55 years $(54+14) \quad 55$ years $(54+12) \quad 1$

$2: 3$

$1: 1$

0.45

$75 \%$

$88 \%$

0.2

$19 \%$

$12 \%$

0.5

$39 \%$

$38 \%$

0.94

$15 \%$

$19 \%$

7.5 years

6.25 Years

$55 \%$

$68 \%$

0.3

$27 \%$

$25 \%$

0.9

$18 \%$

$24 \%$

0.5

$30 \%$

$44 \%$

0.2

$17 \%$

$30 \%$

0.2

6

$50 \%$

$100 \%$

0.002

TABLE 2: Comparison of self-reported responses among cannabinoid non-users and users in a rheumatology clinic.

VAS: visual analog scale. 


\section{Cureus}

Section 4: Perception

On an average, a patient spent anywhere between 2,500 and 5,000 pounds per annum on these alternative therapies but were still happy to recommend it to friends and family. Overall $49 \%$ of patients believed that cannabinoids should be available as a prescription drug in NHS while many of the non-users seemed interested to know more about it.

\section{Comparison of GP and patient responses}

On comparing the perception of GPs and patients in pain management in rheumatology with CBDs, there was a statistically significant difference regarding the awareness and effectiveness $(\mathrm{p}<0.001)$. While the patients advocated the availability of cannabinoids through NHS, GPs were reluctant about it (Table 3).

\begin{tabular}{|c|c|c|c|}
\hline & Rheumatology patients, $n=102$ & Primary care physicians, $n=100$ & p-value \\
\hline Have you heard about complementary medicine? & $65 \%$ & $42 \%$ & $<0.001$ \\
\hline How much does it help in pain? & $8+1.5$ & $3.2+2.5$ & $<0.001$ \\
\hline Would you recommend its use in? & $75 \%$ & $14 \%$ & $<0.001$ \\
\hline Should it be available as NHS prescription? & $48 \%$ & $27 \%$ & 0.002 \\
\hline Diagnosis & & * & \\
\hline Fibromyalgia & $19 \%$ & $41 \%$ & 0.001 \\
\hline Rheumatoid arthritis & $54 \%$ & $29 \%$ & $<0.001$ \\
\hline Osteoarthritis & $23 \%$ & $20 \%$ & 0.5 \\
\hline Connective tissue diseases & $4 \%$ & $10 \%$ & 0.17 \\
\hline
\end{tabular}

TABLE 3: Perception of cannabinoid usage in rheumatology.

GPs: General Practitioners.

While GPs believed that the most common indication for usage of cannabinoids was FMS (41\%), patients reported RA $(54 \%)(\mathrm{p}=0.001)$.

\section{Discussion}

To the best of our knowledge, this is one of the first studies conducted in the UK, assessing the perception of rheumatology patients and primary care physicians regarding cannabinoid usage in rheumatology. Over the last decade use of cannabinoids as complementary medicine has expanded drastically with many countries now legalizing it for various indications including pain.

We conducted a narrative literature review and found several studies from Canada, the USA, Australia, Israel and Ireland regarding perception and experience of cannabinoids among primary care physicians and rheumatologist (Table 4). 


\section{Cureus}

\begin{tabular}{|c|c|c|}
\hline Survey & Survey group & Conclusion \\
\hline $\begin{array}{l}\text { Kondrad } \\
\text { et al. } \\
\text { (2011) [13] }\end{array}$ & $\begin{array}{l}\text { Colorado } \\
\text { Academy of } \\
\text { Family } \\
\text { Physicians }\end{array}$ & $\begin{array}{l}46 \% \text { said that physicians should not recommend marijuana as a medical therapy at all } 80 \% \text { agreed } \\
\text { that training should be incorporated into medical school curricula, } 27 \% \text { of those surveyed agreed } \\
\text { that there were significant physical health benefits }\end{array}$ \\
\hline $\begin{array}{l}\text { Fitzcharles } \\
\text { et al. } \\
\text { (2013) [14] }\end{array}$ & $\begin{array}{l}\text { Canadian } \\
\text { Rheumatologists }\end{array}$ & $\begin{array}{l}75 \% \text { lacked confidence in their knowledge of cannabinoid } 45 \% \text { believed there was no current role } \\
\text { for cannabinoids in rheumatology patient care Only } 25 \% \text { supported any use of herbal cannabis. } 70 \% \\
\text { never having previously prescribed or recommended any cannabinoid treatment }\end{array}$ \\
\hline $\begin{array}{l}\text { Fitzcharles } \\
\text { et al. } \\
\text { (2014) [15] }\end{array}$ & $\begin{array}{l}\text { Rheumatology } \\
\text { Associations of } \\
\text { Canada and } \\
\text { Israel }\end{array}$ & $\begin{array}{l}\text { Three-quarters of responders in both countries were not confident about their knowledge of } \\
\text { cannabinoid molecules or ability to write a prescription for herbal cannabis }\end{array}$ \\
\hline $\begin{array}{l}\text { Karanges } \\
\text { et al. } \\
\text { (2018) [16] }\end{array}$ & $\begin{array}{l}\text { Australian } \\
\text { General } \\
\text { Practitioners }\end{array}$ & $\begin{array}{l}61.5 \% \text { reported one or more patient enquiries about medicinal cannabis Most felt that their own } \\
\text { knowledge was inadequate. Only } 28.8 \% \text { felt comfortable discussing medicinal cannabis with } \\
\text { patients. } 56.5 \% \text { supported availability on prescription, with support for condition-specific use in } \\
\text { cancer pain, palliative care and epilepsy. The majority of GPs are supportive or neutral with regards } \\
\text { to medicinal cannabis use. }\end{array}$ \\
\hline $\begin{array}{l}\text { Crowley et } \\
\text { al. (2017) } \\
{[17]}\end{array}$ & $\begin{array}{l}\text { Irish general } \\
\text { practitioner }\end{array}$ & $\begin{array}{l}\text { Majority did not support decriminalization but supported legalising for medical use. } 60 \% \text { agreed that } \\
\text { cannabis can have a role in palliative care, pain management and treatment of multiple sclerosis (MS) }\end{array}$ \\
\hline $\begin{array}{l}\text { Philpot et } \\
\text { al. (2018) } \\
\text { [18] }\end{array}$ & $\begin{array}{l}\text { Primary care } \\
\text { providers in } \\
\text { Minnesota- } \\
\text { based } \\
\text { healthcare } \\
\text { system }\end{array}$ & $\begin{array}{l}58 \% \text { support medical cannabis as a legitimate medical therapy } 38.7 \% \text { believed that providers should } \\
\text { be offering to patients for managing medical conditions. }>50 \% \text { ) of providers believed that medical } \\
\text { cannabis was helpful for treating the qualifying medical conditions of cancer, terminal illness, and } \\
\text { intractable pain }\end{array}$ \\
\hline $\begin{array}{l}\text { Sideris et } \\
\text { al. (2018) } \\
\text { [19] }\end{array}$ & $\begin{array}{l}\text { New York } \\
\text { Physicians }\end{array}$ & $\begin{array}{l}75 \% \text { reported having patients who used cannabis for symptom control. } 50 \% \text { reported having } \\
\text { patients who inquired about it. Pain was a common symptom for which cannabis was recommended } \\
\text { by registered physicians ( } 69 \% \text { ) and purportedly used by patients }(83 \%) .84 \% \text { believed opioids have } \\
\text { greater risks than cannabinoids }\end{array}$ \\
\hline $\begin{array}{l}\text { Ablin et al. } \\
\text { (2016) [20] }\end{array}$ & $\begin{array}{l}\text { Israeli Society of } \\
\text { Rheumatology }\end{array}$ & $\begin{array}{l}\text { Three-quarters of responders were not confident about their knowledge of cannabinoid. } 78 \% \text { were } \\
\text { not confident to write a prescription for herbal cannabis. } 74 \% \text { of responders held the opinion that } \\
\text { there was some role for cannabinoids in the management of rheumatic disease }\end{array}$ \\
\hline
\end{tabular}

TABLE 4: Narrative literature review of physician/rheumatologist surveys.

Unlike the UK, some of these states have legalised cannabinoids in pain management. The responses of these studies are in line with our findings, wherein most clinicians still do not advocate the usage of cannabinoids in chronic pain, have inadequate knowledge, less confident and have reservations regarding their legal status. On the contrary, the patient reported response from our study to support the usage of cannabinoids in rheumatic pain.

This study raises some important concerns. There is limited confidence and lack of knowledge among GPs regarding cannabinoid usage. Furthermore, in the setting of increase demand by the patients, there is an imbalance between need, advocacy and knowledge. This serious gap covers many aspects of cannabinoids including uncertainty of content, unspecified dosing, lack of clear recommendations or guidelines and drug interactions.

This disconnect sometimes results in difficult consultation and puts a strain on the physician-patient relationship.

Our group of patients attending regular rheumatology clinics reported using CBD more for pain in RA as compared to OA/FMS. This needs to be explored further particularly in context with possible drug interactions and failure to meet the treat to target concept [10].

We also noted a lack of self-reported adverse effects by the patients which could be due to appropriate safety profile or reduced concentration of THC in the preparation used. 
There was a difference in the perception of GPs regarding the use and benefits of cannabinoids in their patients compared to actual patient reported data. Possible explanation could be that GPs come across more FMS patients in their daily practice when compared to rheumatology patients.

Strength of our study includes a good response rate and two arms comparing GPs and patient responses. The ubiquitous nature of the endocannabinoid system raises questions as to the exact function of this system in health and disease, with limited experience in the clinical arena. The cannabinoid effects are not only confined to the nervous system and pain pathways, but also have roles in inflammation and immunemodulatory effects [11]. Thus their role in the management of rheumatological issues as immunemodulators are also being explored and could be one of the reasons for their effectiveness in patients as supported by self-reported responses.

Limitation of our study is the sample size given the popularity and abundant utilisation of cannabinoids by our patients. Although $16 \%$ of our patients reported using cannabinoids, we believe this to be underreported and a larger study can decipher a much superior figure. In a paired survey of primary care providers(PCP) and their patients it was found that PCPs were aware of marijuana use in their patients only $53 \%$ of the time [12]. While the comparison of improvement in pain between conventional therapy and cannabinoids in the study is not ideal, it gives us an indication that those who use them are reasonably satisfied.

In 2016, a Canadian study reported 3.8\% of patients using cannabinoids. Most common indication (almost half) was OA. They reported users as younger, more likely unemployed or disabled, and having poorer global health [21]. Our study in contrast has a much higher prevalence of consumers (16\%). Recent easy availability and access in different forms could be one of the reasons. We did not demonstrate any significant difference in terms of demography or employment status. One of the reasons for better mental health could be difference in the form of cannabinoids used among our patients. Smoking presents an uncontrolled delivery system with potential harm due to inhaled toxic substances. Sativex (CBD:THC 1:1) when administered through oro-mucosal route resulted in lower plasma levels of THC as compared with the levels achieved following inhalation at a similar dose [22]. Majority of our patients reported using oral forms which could be the reason for low psychomotor adverse events reported. Also, THC which is the component responsible for psychoactive effects is lacking in the commonly available over-the-counter preparations.

Thus we believe the lack of knowledge among GPs stems from the paucity of clinical information regarding the use of cannabinoids in rheumatology practice. To date, there is not a single controlled clinical study that has examined the efficacy or safety of herbal cannabis in the rheumatic diseases [23]. There is a clear knowledge gap between the current science and treating clinician. This study demonstrating efficacy through patient-reported response would pave way for further studies.

\section{Conclusions}

Despite the lack of evidence-based medicine, rheumatology patients have access and use CBD products, sometimes without the knowledge of healthcare professionals. There is a significant difference between patient and physician perception on the use of cannabinoids as a therapeutic agent in rheumatic pain. Quality research and clinical trials are in need of the hour; however, until we have more evidence, health care professionals should currently dissuade rheumatology patients from using cannabinoids.

\section{Additional Information \\ Disclosures}

Human subjects: Consent was obtained or waived by all participants in this study. Animal subjects: All authors have confirmed that this study did not involve animal subjects or tissue. Conflicts of interest: In compliance with the ICMJE uniform disclosure form, all authors declare the following: Payment/services info: All authors have declared that no financial support was received from any organization for the submitted work. Financial relationships: All authors have declared that they have no financial relationships at present or within the previous three years with any organizations that might have an interest in the submitted work. Other relationships: All authors have declared that there are no other relationships or activities that could appear to have influenced the submitted work.

\section{References}

1. Katz-Talmor D, Katz I, Porat-Katz B, et al.: Cannabinoids for the treatment of rheumatic diseases - where do we stand?. Nat Rev Rheumatol. 2018, 14:488-498. 10.1038/s41584-018-0025-5

2. Fukuda S, Kohsaka H, Takayasu A, et al.: Cannabinoid receptor 2 as a potential therapeutic target in rheumatoid arthritis. BMC Musculoskelet Disord. 2014, 15:275-2014. 10.1186/1471-2474-15-275

3. Gui H, Liu X, Liu LR, Su DF, Dai SM: Activation of cannabinoid receptor 2 attenuates synovitis and joint distruction in collagen-induced arthritis. Immunobiology. 2015, 220:817-822. 10.1016/j.imbio.2014.12.012

4. NICE. Cannabis-based medicinal products. NICE Guideline 144. (2019). http://www.nice.org.uk/ng144. 
5. Home Office Circular 2018: Rescheduling of cannabis-based products for medicinal use in humans. Crime, Policing and Fire Group (CPFG) Drugs and Alcohol Unit. (2018). Accessed: 5 December 2018:

6. Deshpande PR, Rajan S, Sudeepthi BL, Abdul Nazir CP: Patient-reported outcomes: a new era in clinical research. Perspect Clin Res. 2011, 2:137-144. 10.4103/2229-3485.86879

7. Ware MA, Adams H, Guy GW: The medicinal use of cannabis in the UK: results of a nationwide survey . Int J Clin Pract. 2005, 59:291-295. 10.1111/j.1742-1241.2004.00271.x

8. Ste-Marie PA, Fitzcharles MA, Gamsa A, Ware MA, Shir Y: Association of herbal cannabis use with negative psychosocial parameters in patients with fibromyalgia. Arthritis Care Res. 2012, 64:1202-1208. 10.1002/acr.21732

9. Brooks E, Gundersen DC, Flynn E, Brooks-Russell A, Bull S: The clinical implications of legalizing marijuana: are physician and non-physician providers prepared?. Addict Behav. 2017, 72:1-7. 10.1016/j.addbeh.2017.03.007

10. Wilson-Morkeh H, Al-Abdulla A, Sien L, Mohamed H, Youngstein T: Important drug interactions exist between cannabidiol oil and commonly prescribed drugs in rheumatology practice. Rheumatology. 2020, 59:249-251. 10.1093/rheumatology/kez304

11. Vuckovic SM, Srebro D, Vujovic KS, et al.: Cannabinoids and pain: new insights from old molecules. Front Pharmacol. 2018, 9:1259. 10.3389/fphar.2018.01259

12. Kondrad EC, Reed AJ, Simpson MJ, Nease DE: Lack of communication about medical marijuana use between doctors and their patients. J Am Board Fam Med. 2018, 31:805-808. 10.3122/jabfm.2018.05.170462

13. Kondrad E, Reid A: Colorado family physicians' attitudes toward medical marijuana . J Am Board Fam Med. 2013, 26:52-60. 10.3122/jabfm.2013.01.120089

14. Fitzcharles M, Ste-Marie PA, Clauw DJ, et al.: Rheumatologists lack confidence in their knowledge of cannabinoids pertaining to the management of rheumatic complaints. BMC Musculoskelet Disord. 2014, 15:258. 10.1186/1471-2474-15-258

15. Fitzcharles M, Ste-Marie PA, Ablin JN, Shir Y: Comparison of Canadian and Israeli rheumatologists' understanding of cannabinoid use as a therapy for rheumatic diseases. Ann Rheum Dis. 2014, 73:1177. 10.1136/annrheumdis-2014-eular.2511

16. Karanges EA, Suraev A, Elias N, Manocha R, McGregor IS: Knowledge and attitudes of Australian general practitioners towards medicinal cannabis: a cross-sectional survey. BMJ Open. 2018, 2018:e22101. 10.1136/bmjopen-2018-022101

17. Crowley D, Collins C, Delargy I, et al.: Irish general practitioner attitudes toward decriminalisation and medical use of cannabis: results from a national survey. Harm Reduct J. 2017, 14:4. 10.1186/s12954-0160129-7

18. Philpot LM, Ebbert JO, Hurt RT: A survey of the attitudes, beliefs and knowledge about medical cannabis among primary care providers. BMC Fam Pract. 2019, 20:17. 10.1186/s12875-019-0906-y

19. Sideris A, Khan F, Boltunova A, Cuff G, Gharibo C, Doan LV: New York physicians' perspectives and knowledge of the state medical marijuana program. Cannabis Cannabinoid Res. 2018, 3:74-84. 10.1089/can.2017.0046

20. Ablin JN, Elkayam O, Fitzcharles M-A: Attitudes of Israeli rheumatologists to the use of medical cannabis as therapy for rheumatic disorders. Rambam Maimonides Med J. 2016, 7:e0012. 10.5041/RMMJ.10239

21. Ste-Marie PA, Shir Y, Rampakakis E, et al.: Survey of herbal cannabis (marijuana) use in rheumatology clinic attenders with a rheumatologist confirmed diagnosis. Pain. 2016, 157:2792-2797. 10.1097/j.pain.0000000000000706

22. Huestis MA: Human cannabinoid pharmacokinetics. Chem Biodivers. 2007, 4:1770-1804. 10.1002/cbdv.200790152

23. Fitzcharles M, Ste-Marie PA, Häuser W, et al.: Efficacy, tolerability, and safety of cannabinoid treatments in the rheumatic diseases: a systematic review of randomized controlled trials. Arthritis Care Res. 2016, 68:681-688. 10.1002/acr.22727 